\title{
Security Dilemma of Rohingya Refugees in Malaysia
}

\author{
Rizwan Rafi Togoo1, Farah Hanim Binti Mohamed Ismail² \\ ${ }^{1}$ Leiden University, Leiden, Netherlands \\ ${ }^{2}$ Asia Pacific University, Kuala Lumpur, Malaysia \\ Email: togoorizwan@gmail.com, farah.hanin@cyberjava.edu.my
}

How to cite this paper: Togoo, R. R., \& Ismail, F. H. B. M. (2021). Security Dilemma of Rohingya Refugees in Malaysia. Open Journal of Political Science, 11, 12-20. https://doi.org/10.4236/ojps.2021.111002

Received: November 12, 2020

Accepted: January 4, 2021

Published: January 7, 2021

Copyright (c) 2021 by author(s) and Scientific Research Publishing Inc. This work is licensed under the Creative Commons Attribution International License (CC BY 4.0).

http://creativecommons.org/licenses/by/4.0/

\begin{abstract}
This research has discussed the background and factors that caused the Rohingya humanitarian crisis, which forced tens of thousands of Rohingya men, women, and children to flee oppression in the Rakhine state. The information gathered from the personal interviews conducted for research purposes gave us a brief historical background of the conflict. This study employed a qualitative method of research. It aims to analyze the difficulties the Rohingya refugees face by taking the individual stories of human beings. We also analyze the civil society's steps, the government of Malaysia, and other organizations, both governmental and non-governmental, to assist the Rohingya refugees in tackling these issues. The study recommends that the Malaysian government should make efforts to provide education, financial support, and jobs to Rohingya refugees, giving them the right to live a better life.
\end{abstract}

\section{Keywords}

Rohingya Refugees, Malaysia, Security, UNHCR

\section{Introduction}

The Rohingya (also known as Arakanese) are an ethnic group of Indo-Aryanspeaking people from the state of Rakhine of the Republic of the Union of Myanmar (formerly known as Burma); since the controversial 1982 citizenship law, the Rohingya people are not officially recognized by the Myanmar government as a registered ethnic group and are considered to be stateless. The Rohingya people themselves prefer to be called Ruáingga; the term "Rohingya" may come from Rakhanga or Roshanga, the words for the state of Arakan, which suggests that the term Rohingya can be referred to as "inhabitant of Rohang", which was the early Muslim name for Arakan. Rohingya people's ethnicity has 
been a matter of debate and discussion (Leider, 2013). Chia, 2016 writing for The Diplomat states that "the Rohingya are not an ethnic, but rather a political construction."

The Rohingya community of Myanmar is often termed as the most persecuted group of people in the world, with the situation being compared to being at par with the Palestinians and Roma. As per (Pitman, 2012): “They have been called ogres and animals, terrorists, and much worse when their existence is even acknowledged. Asia's more than 1 million ethnic Rohingya Muslims are among the most persecuted people on Earth. Most live in an anachronistic purgatory without passports, unable to travel freely or call any place home".

The present research was done to identify the causes for the Rohingya humanitarian crisis, analyze the factors that led the Rohingya refugees to seek sanctuary in Malaysia, and discuss the role of the government and Malaysia's civil society in protecting the rights and security of the Rohingya refugees. This study is concerned with the social science field. The nature of this study is mainly comparative and analytical. This research's scope was an analysis of the human security of the Rohingya refugees fleeing persecution in Myanmar in Malaysia. This research was done to shed light on the role of the Malaysian government and civil society in protecting the Rohingya refugees' human rights and will also analyze the factors that led the Rohingya refugees to seek asylum in Malaysia.

Historical perspective and present situation: The Rohingya humanitarian crisis traces its roots to the series of violent sectarian clashes that took place in Rakhine State, Myanmar (formerly known as Arakan) between the Rakhine Buddhist and Rohingya Muslim communities and also attacks on the Rohingya civilians by Myanmar's security forces. This resulted in the Rohingya Refugee crisis which was a mass human exodus of thousands of Rohingya people from Myanmar as well as Bangladesh to mainly Southeast Asian countries including Malaysia, Indonesia, and Thailand. This migration was collectively termed as "boat people" by the mainstream international press.

A group of researchers from the International State Crime Initiative (ISCI), based at Queen Mary University of London (QMUL), in their report from October 2015, have claimed to have found substantial proof that the Rohingya face mass annihilation and are in the final stages of a genocidal process (Green, 2015).

As a result of this massive crackdown on the Rohingya community, an estimated 92,000 Rohingya people have been displaced externally, and 23,000 internally, and around 65,000 had fled from Myanmar into neighboring Bangladesh between October 2016 and January 2017 (Solmon, 2017).

The United Nations Secretary-General António Guterres described the situation involving the Rohingya Myanmar's Rakhine state as "catastrophic" (BBC, 2017).

Humanitarian crisis: According to Amnesty International in its annual report covering 159 countries, the humanitarian crisis faced by the Rohingya people in Myanmar was the result of a "hate-filled rhetoric" when society en- 
couraged to hate and a lack of global leadership on human rights and leaders normalizing discrimination against minorities (Reuters Staff, 2018). After the independence of Myanmar from British colonialism in 1948, the Rohingya enjoyed equal rights as every other ethnic group in Myanmar, and this denial of citizenship came as an overnight shock. As of 2017, since the outbreak of the Rohingya humanitarian crisis, which has forced hundreds of thousands of Rohingya to seek safety in various countries, an estimated 60,000 Rohingya refugees have been living in Malaysia.

After the refugee migration following the 2012 sectarian clashes in Rakhine, which compelled the Rohingya people to flee by boat from the Bay of Bengal, what has been termed as "the largest regional outflow of asylum seekers by the sea in decades". On 20 May 2015 permitted the asylum-seekers to stay temporarily for one year on the condition that the international community repatriates them after the one-year time limit expires; while it was clear that resettlement of all the refugees within a year was an unachievable task, this enabled the governments to keep their reputation intact and at the same time not substantively changing their policy and practice towards asylum seekers. Currently, the Rohingya make up a vast majority of asylum seekers and refugees in Malaysia. The majority of them around the capital Kuala Lumpur, and the surrounding Klang Valley, though there are also sizable populations in other areas of the country, including Penang, Johor, and Malacca. A 2012 report evaluating the implementation of UNHCR urban refugee policy in Malaysia aptly describes refugees' context, stating: "Malaysia can be considered a 'country of asylum.' Refugees in Malaysia have been and continue to be at risk of arrest, detention, extortion and corporal punishment, although the frequency of such incidents has diminished in recent times. Official restrictions prevent refugees from working in the formal sector of the economy, accessing healthcare on the same basis as nationals and attending Malaysian schools." (Wake, 2016).

At the moment, there is no existing refugee law in Malaysia or any legal, poli$\mathrm{cy}$, or administrative framework for responding to refugees, which translates into the fact that the government of Malaysian does not provide direct protection or assistance to refugees on its territory (Equal Rights Trust and Institute of Human Rights and Peace Studies, 2014).

Factors that led the Rohingya refugees to seek sanctuary in Malaysia: The factors that can be observed as reasons for the Rohingya to seek refuge in Malaysia are that unlike neighboring ASEAN countries, Malaysia had allowed access to their territory to the Rohingya asylum seekers arriving via the sea, an instance being that of December 2013 when Malaysia allowed entry to 40 Rohingya refugees who were rescued from drenching in the Bay of Bengal which received a positive response and acclamation among the International community and media. The report (Equal Rights Trust and Institute of Human Rights and Peace Studies, 2014) also mentions that in addition to the recent arrivals of refugees via the sea, there has also been an informally settled Rohingya community throughout Malaysia for two to three generations. Thus, there is a lesser chance of feeling of 
alienation or isolation compared to other countries for the Rohingya refugees. It is also mentioned that there is a certain extent of acceptance towards foreigners or asylum seekers in Malaysia due to cheap labor in some factories where Malaysian nationals have shown reluctance to work. Another factor mentioned in this report is the presence of a United Nations High Commissioner for Refugees (UNHCR) representative office in Malaysia, which holds the responsibility of protecting (in the form of registration and documentation) refugees and stateless people, including the Rohingya. The UNHCR also aids refugee children in education in schools, especially for children and healthcare facilities. The report also mentions that most Rohingya refugees staying in Malaysia prefer to remain there instead of being relocated to a third country with an existing refugee protection law. The reason being that the Rohingya feel they have a better social structure, and also Islam being the dominant and state religion in Malaysia provides them a sense of inclusiveness. A Rohingya leader in Malaysia, as per the report, was quoted saying: I would prefer to live in Malaysia instead of the United States because the U.S. is not an Islamic country. I have stayed in Malaysia for 16 years and know how to speak, read, and write well in the Malay language. I did not get everything that I wanted, but I stayed in Malaysia on Islamic grounds. In a research paper titled "Livelihood strategies of Rohingya refugees in Malaysia, We want to live in dignity," authored by (Wake, 2016) for Humanitarian Policy Group, we are given an insight into the background and major issues faced by Rohingya refugees living in Malaysia. The authors highlight how the ASEAN nations like Malaysia, Indonesia, and Thailand initially send back the Rohingya refugee boats away from their waters and only after massive International pressure agreed to provide temporary shelter on the condition that the International community resettles them within one year (Wake, 2016). While providing an analysis on the situation of refugees in Malaysia, the Authors mention the fact that currently there are 158,510 asylum seekers and refugees in Malaysia under the registration of the UNHCR, with 44,870 of them being Rohingya. Another important point mentioned by the author in this research is the de facto integration factor concerning Rohingya refugees in Malaysia. The authors mention that upon interviewing various individuals from the Rohingya community in Malaysia, it was observed that many of them were able to communicate in the local language while working for their local employers. A certain number of refugees also spoke of a close human bond they have developed with Malaysia's local population; this includes their friends and neighbors. One of the main driving factors behind this de facto integration, as observed by the authors, is religion. The Rohingya practice Islam, Malaysia's state religion, and many of them spoke of the bond formed by attending prayers in the local mosques regularly.

Rohingya practice Islam, Malaysia's state religion, and many of them spoke of the bond formed by attending prayers in the local mosques regularly.

Rights and security of the Rohingya refugees: The majority of the Rohingya refugees who entered Malaysia after the May 2011 boat crisis was considered illegal migrants and were detained for more than a year at the Belantik Immigra- 
tion Detention Center (IDC) in northern Malaysia. The report also explicitly highlights Rohingya families' incidents (particularly children) upon reaching the coast and being detained by the Malaysian police being separated from their families. The author also mentions Rohingya refugees' accounts of the unhygienic and mismanaged condition of the detention centers, which was so overcrowded that detainees had to take turns to lie down to sleep. The report states that nearly every Rohingya refugee interviewed has expressed fear of being detained by the police or other law enforcement authorities. Although Malaysia, although having a presence of thousands of Rohingya refugees, has not signed the 1951 refugee convention, and hence the Rohingya are deemed, illegal migrants.

UNHCR has provided the Rohingya refugees with UNHCR ID Cards with the Rohingya refugees' view as their most important form of protection and the only form of defense they have against detention, and it also helps them find jobs. UNHCR has been doing with the Malaysian government in ensuring sustainable health insurance for the Rohingya refugees Refugee Medical Insurance (REMEDI). The UNHCR has provided funds and donations to these learning centers, which the report terms as "limited".

The government and the civil society, particularly NGOs like the UNHCR and other local ones, should set up a proper mechanism to address the primary concerns such as housing, health, and livelihood.

The Rohingya crisis is a major security threat for maritime nations like Malaysia. Rohingya refugees who still have not registered themselves and are forced into an uncertain life are always at risk of being arrested by authorities. This life of precariousness can force such refugees into transnational organized crime resulting in enforcement issues for the Malaysian government. The Rohingya are vulnerable to be recruited by militant groups to broaden their presence in Southeast Asia. The extremist organizations offer refugees the basic needs which the host country fails to provide.

The author also analyzes the role of the Malaysian civil society in protecting the refugee community's rights. The author cites the instance of Amnesty International (AI), which called on the government of Malaysia to immediately provide protection and legal status to the refugees ( $\mathrm{Ai}, 2016)$.

\section{Research Methodology}

This research employed a qualitative method of research. For this research, the methods used included both primary and secondary sources, and the nature of the research was purely qualitative. The reason for adopting this research method was that there is a surplus availability of journals and articles that cover the issue of the conflict in Myanmar and the issues concerning Rohingya refugees settled in Malaysia and beyond. This research also aimed to analyze the steps taken by the civil society, the government of Malaysia, and other organizations, both governmental and non-governmental, to assist the Rohingya refugees in 
tackling these issues. This research's findings were based on material collected from secondary sources such as books, journals, articles, and other sources of information available on the internet. The primary sources of information were interviews conducted either by email or face to face with people relevant to the topic this can include government officials, members of the Malaysian civil society, members of NGOs who work for the welfare of the asylum seekers as well as interest groups formed to represent the Rohingya refugees. In this research, the interviews conducted were open ended in nature where the interviewee answered questions asked by the interviewer that is significant concerning the research. At least four interviewees were considered enough to fulfill the requirement and obtain the required information for this research. The questions vary depending on whether the interviewee belongs to any government institution or civil society group. The material collected from these interviews was either face to face or email interviews. This research's secondary research method includes data collected from online journals, articles, books, and newspapers. Most of the material used for secondary research purpose are regarding the situation of the Rohingya refugees in Malaysia and contains diverse opinions and analysis.

The questionnaire's primary focus and the research objectives were to find out about the social, economic, and legal status of Rohingya refugees in Malaysia. Through the research, the aim was to analyze the difficulties the Rohingya refugees faced and take individual stories of human beings.

Dependent Variable: Security dilemma of Rohingya refugees in Malaysia

Three independent variables in the study that affects the dependent

1) The causes of the Rohingya humanitarian crisis.

2) Factors that led the Rohingya refugees to seek sanctuary in Malaysia.

3) Role of the Malaysian government and civil society.

\section{Research Outcomes}

From the interview, we observed various findings. The Rohingya face difficulties not only in Myanmar but also on their journey to Malaysia and also in Malaysia itself. The refugees said that they suffer from poverty due to the denial of jobs, and many of them were unable to afford medical treatment if any member of the family falls sick. Lack of education was observed among the Rohingya refugee children, especially those orphaned and without any family or guardians. Rohingya women who were victims of domestic abuse, human trafficking, and sexual abuse, many of these women who do not have a UNHCR card cannot get any protection from the government or UNHCR.

Currently, the Rohingya numbered between 150,000 - 200,000 in Malaysia is the most significant refugee population in Malaysia and the biggest Rohingya population in any ASEAN country outside Myanmar. Malaysia is a Muslim majority country with Islam as the country's official religion, gives a sense of security to the Rohingya who for many years faced persecution as a religious minority. Many of the Rohingya refugees were tricked by human traffickers. They en- 
couraged them to be illegally trafficked to Malaysia and presented Malaysia to them as a Muslim majority country that would accept them and grant them asylum and citizenship without any qualms.

The difficulties faced by Rohingya refugees in Malaysia: The Rohingya refugees came to Malaysia fleeing persecution and denial of fundamental human rights that every human being in this civilized world is entitled to. The Rohingya refugees' three significant issues in Malaysia are lack of legal documentation, restricting their freedom of movement. This contributes to other difficulties such as no employability that denies them a source of livelihood and the third being denial of proper education to Rohingya refugee children.

1) The biggest concern concerning the Rohingya refugees in Malaysia is their security; even if they have a UNHCR card as identity proof, it does not guarantee them not being arrested or detained by the police. The second major issue they face is a denial of proper education to their children.

2) There is still no proper school for the community, and the only education they receive is from unrecognized informal educational facilities run by NGOs, which is not enough to allow them to further their studies to the university level. Ultimately, most Rohingya, even in Malaysia, remain illiterate and contribute to a bleak future.

3) Lack of medical access. Many of the Rohingya babies born in Malaysia are unable to get proper vaccinations because they cannot afford the medical bills for foreigners in Malaysia. The Rohingya refugees' conditions are very unhygienic, and the risk of infectious diseases spreading is very high.

4) No legal protection from the law

5) Rohingya women and girls in Malaysia are victims of human trafficking, child marriage, and physical abuse.

6) Rohingya families living in Malaysia for two to three generations, even with the UNHCR card, are still unable to go to proper public schools and cannot make a living for themselves because they are not allowed to work as per the Malaysian law.

7) Many of the Rohingya cannot afford the medical bills for foreigners in Malaysia, another primary concern.

The UNHCR has had a presence and has been operating in Malaysia since 1975 when asylum seekers from Vietnam arrived via boat and have since been working towards helping them settle in third countries or send them back to their hometown when it is safe to do so.

The Rohingyas numbering between 150 - 200,000, are by far the biggest refugee community in Malaysia. However, roughly only 60,000 of them have the UNHCR card, which categorizes them as refugees, i.e., most of them are considered illegal migrants, which subjects them to the risk of being arrested or detained by the police. The interviewees were what they feel is the reason behind this.

The Malaysian civil society and government do work:

1) Rohingya Vision is the first-ever satellite television channel representing 
the Rohingya community worldwide and acting as a watchdog for the Rohingyas, with their headquarters currently in Kuala Lumpur.

2) The Malaysian government currently does not have any policy to ratify the refugee convention but has allowed NGOs to provide public services. The local authorities also provide individual assistance like better access to health to the Rohingyas.

3) UN refugee convention is being helpful by allowing hundreds and thousands of Rohingya to stay. The organization also works with their doctors and volunteers to provide free medical services and health screenings to the Rohingya refugees. They also provide them assistance in terms of other aid like food and clothing to families identified by them who urgently need such assistance.

4) The organization has been working towards gender equality in the community and help refugee women and girls who are victims of human trafficking and sexual abuse. The organization has helped rescue several young female victims who were sold off by human traffickers and help them in their rehabilitation.

5) The organization aims to train and educate the Rohingyas to act as a force for their society and positively contribute to society.

\section{Conclusion}

The research is directed towards the students who wish to pursue research on the Rohingya community living in Malaysia. Going through this research can positively impact these students and provide them with relevant details about the Rohingya refugees, and ultimately provide them the information they are seeking. The major limitation of this research is that the researcher would not travel to Myanmar and observe the past and current events that occurred with the Rohingya people in Rakhine. It may be hard or even beyond the researcher's reach to gain access to specific data and facts from the Malaysian government concerning Rohingya refugees since many security issues are associated with it. Due to time constraints from both sides, the researcher might not interview officials from the Malaysian government. This research's targeted audience also includes International Organizations, Diplomatic missions, Academic researchers, and Non-Governmental Organizations. Based on the research done for this study, it is recommended that the Malaysian government should ensure that the Rohingya refugee children get a proper and formal education. Efforts should be made for financial and moral support, and Rohingya refugees' employment in the private and public sector.

\section{Conflicts of Interest}

The authors declare no conflicts of interest regarding the publication of this paper.

\section{References}

Ai, C. L. C. (2016). Refugee Representation in Malaysia: A Study of Media Representa- 
tions and Personal Narratives (p. 397). Kuala Lumpur: Faculty of Languages \& Linguistics, University of Malaya.

BBC (2017). Rohingya Crisis: Humanitarian Situation Catastrophic, UN Says. https://www.bbc.com/news/world-asia-41260767

Chia, J. (2016). The Truth about Myanmar's Rohingya Issue. https://thediplomat.com/2016/03/the-truth-about-myanmars-rohingya-issue

Equal Rights Trust and Institute of Human Rights and Peace Studies (2014). Equal Only in Name: The Human Rights of Stateless Rohingya in Malaysia (p. 117). Bangkok: Institute of Human Rights and Peace Studies, Mahidol University.

Green, P. (2015). Countdown to Annihilation: Genocide in Myanmar (p. 111). International State Crime Initiative.

Leider, J. P. (2013). Rohingya: The Name, the Movement, the Quest for Identity (p. 26). Nation Building in Myanmar.

Pitman, T. (2012). Myanmar Conflict Spurs Hatred for Asia's Outcasts. https://www.washingtonexaminer.com/myanmar-conflict-spurs-hatred-for-asias-outca sts

Reuters Staff (2018). Amnesty Says Rohingya Crisis Consequence of Society Encouraged to Hate.

https://www.reuters.com/article/us-amnesty-report/amnesty-says-rohingya-crisis-cons equence-of-society-encouraged-to-hate-idUSKCN1G60EA

Solmon, F. (2017). Myanmar's Crisis, Bangladesh's Burden: Among the Rohingya Refugees Waiting for a Miracle. http://time.com/5031342/bangladesh-myanmar-rohingya-refugee-crisis

Wake, C. (2016). Livelihood Strategies of Rohingya Refugees in Malaysia: We Want to Live in Dignity (p. 52). Humanitarian Policy Group. 